\title{
Association study between the -866G/A polymorphism in the promoter of uncoupling protein-2 gene and polycystic ovary syndrome
}

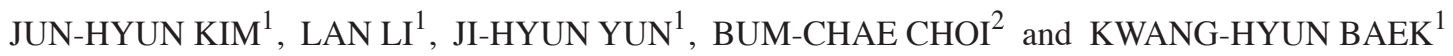 \\ ${ }^{1}$ Department of Biomedical Science, CHA University, CHA General Hospital, Seoul 135-081; \\ ${ }^{2}$ Department of Obstetrics and Gynecology, CL Women's Hospital, Gwangju 502-800, Republic of Korea
}

Received April 22, 2011; Accepted May 16, 2011

DOI: $10.3892 / \mathrm{mmr} .2011 .497$

\begin{abstract}
Polycystic ovary syndrome (PCOS) is a disorder characterized by hyperandrogenism, chronic oligoanovulation and insulin resistance. A number of women with PCOS are obese and exhibit abnormal phenotypes, including high levels of androgens, an irregular menstrual cycle and increased hair growth. Studies on obese PCOS patients have proven the crucial role that obesity plays in insulin resistance and hyperinsulinemia. The uncoupling protein $(U C P)$ gene is one of the genes known to have a strong association with obesity and insulin resistance. Thus, we analyzed the association between the $-866 \mathrm{G} / \mathrm{A}$ polymorphism in the promoter of $U C P 2$ and PCOS. Genotyping was performed by polymerase chain reaction along with restriction fragment length polymorphism analysis, followed by an analysis of the genotype of the UCP2 polymorphism in PCOS and control subjects using HapAnalyzer. The study included samples from 277 PCOS patients and 152 healthy controls. $\mathrm{P}<0.05$ was considered to be statistically significant. In conclusion, no association was found between the $-866 \mathrm{G} / \mathrm{A}$ single nucleotide polymorphism and $\mathrm{PCOS}(\mathrm{P}=0.7168, \mathrm{OR}=1.07,95 \% \mathrm{CI})$. The present study showed that $-866 \mathrm{G} / \mathrm{A}$, a $U C P 2$ gene polymorphism, is not associated with the pathogenesis of PCOS.
\end{abstract}

\section{Introduction}

Polycystic ovary syndrome (PCOS), one of the most common endocrine disorders, affects $5-10 \%$ of women. It is characterized by hyperandrogenism and chronic oligoanovulation (1-6). PCOS patients are reported to have high serum concentrations of androgenic hormones, including testosterone, androstenedione and dehydroepiandrosterone sulfate (DHEA-S) (1-5).

Correspondence to: Professor Kwang-Hyun Baek, Department of Biomedical Science, CHA University, CHA General Hospital, 606-16 Yeoksam 1-Dong, Gangnam-Gu, Seoul 135-081, Republic of Korea E-mail: baek@cha.ac.kr

Key words: obesity, polycystic ovary syndrome, single nucleotide polymorphism, type 2 diabetes
PCOS is also associated with the metabolic syndrome, which is linked to insulin resistance, hyperinsulinemia and obesity. The post-binding defect in the insulin receptor signaling pathway may be one of the reasons for insulin resistance in PCOS, while the high insulin level potentially has have a gonadotropin-augmenting effect on ovarian function $(3,5,7)$. Obesity is also a significant common clinical feature in women affected by PCOS. Over $50 \%$ of patients were found to be overweight or obese $(5,8)$, which may occur due to the onset of oligomenorrhea and hyperandrogenism, suggesting a pathogenic role of obesity in the development of the syndrome (5).

Uncoupling proteins (UCPs) are mitochondrial carrier proteins that uncouple the transport of protons across the inner mitochondrial membrane from electron transport and are involved in the synthesis of ATP from ADP (9-10). The archetypal $U C P 1$ is mainly expressed in brown adipocytes, while $U C P 2$ expression is widely distributed in mammalian tissues, including white adipose tissue, skeletal muscle, pancreatic islets, and the central nervous system (11-13). A number of polymorphisms and mutations in three uncoupling protein homolog genes (UCP1, UCP2 and UCP3) have been reported (10). The polymorphisms in these $U C P$ s have been shown to play a significant role in the pathogenesis of type 2 diabetes (T2D) mellitus and obesity (10). Perturbation in the expression level of $U C P 2$ or altered action of $U C P 2$ leads to $\mathrm{T} 2 \mathrm{D}$, disordered lipid metabolism, impaired insulin secretion and dysfunctional weight homeostasis (10,14-16).

There are three main reported polymorphisms in the UCP2 gene that are associated with changes in body mass index (BMI), energy expenditure and maintenance of body weight after overfeeding $(10,17)$. Various studies have been performed on exon 4 of the $U C P 2$ gene for the substitution of valine (V) for alanine (A) (Ala55Val) or the 45-bp insertion/deletion variant $(10,18)$. If not all, the majority of these polymorphism studies on the UCP2 gene revealed an association with obesity and energy expenditure. Esterbauer et al identified a functional polymorphism located in the promoter region of the UCP2 gene (17). This polymorphism contributes to $71 \%$ of variation in the expression ratio between the insertion and deletion alleles (17). The $-866 \mathrm{~A}$ allele has been shown to enhance or suppress $U C P 2$ transcriptional activity in transfected cultured 
cells $(13,19)$, indicating that $U C P 2$ mRNA levels are associated with the $-866 \mathrm{~A}$ allele. Additionally, the $-866 \mathrm{G}$ allele is associated with an increased risk of chronic inflammatory diseases (20), and susceptibility to autoimmune (21) and cardiovascular diseases (22).

A number of PCOS patients with obesity exhibit the conditions of insulin resistance and hyperinsulinemia. Previous studies demonstrated the mechanism by which obesity may induce an insulin-resistant state in PCOS patients. Additionally, these studies emphasized the role of obesity in amplifying the degree of hyperandrogenism in PCOS $(5,23)$. A growing body of evidence reports that the -866G/A polymorphism of $U C P 2$ is associated with $\mathrm{T} 2 \mathrm{D}$ and obesity $(10,12)$, which led to our hypothesis that the $-866 \mathrm{G} / \mathrm{A}$ polymorphism of $U C P 2$ plays a significant role in obese PCOS patients. The purpose of the present study was to analyze the $-866 \mathrm{G} / \mathrm{A}$ polymorphism in the $U C P 2$ promoter in obese PCOS patients. This was the first study to investigate the association between the $-866 \mathrm{G} / \mathrm{A}$ polymorphism in the promoter of UCP2 and PCOS.

\section{Materials and methods}

Subjects. A total of 429 Korean females, of which 152 were healthy control subjects and 277 were PCOS patients, were selected from the Fertility Center at CHA General Hospital in Seoul, Korea, to participate in this study. The diagnosis of PCOS was based on the criteria proposed by the 2003 ASRM/ ESHRE Rotterdam consensus. This study was approved by the Institutional Review Board (IRB).

DNA extraction and genotyping. For molecular genetic experiments, blood samples from the PCOS patients and the control group were collected in tubes containing EDTA as an anticoagulant and were stored at $4^{\circ} \mathrm{C}$. Genomic DNA was then extracted from the whole blood samples.

The $-866 \mathrm{G} / \mathrm{A}$ variant of $U C P 2$ was amplified using a forward primer: 5'-CAC GCT GCT TCT GCC AGG AC-3' and a reverse primer: 5'-AGG CGT CAG GAG ATG GAC CG-3'. Cycling parameters were as follows: denaturation at $94^{\circ} \mathrm{C}$ for $5 \mathrm{~min}, 30$ cycles at $94^{\circ} \mathrm{C}$ for $30 \mathrm{sec}$, annealing at $65^{\circ} \mathrm{C}$ for $30 \mathrm{sec}$, extension at $72^{\circ} \mathrm{C}$ for $30 \mathrm{sec}$ and a final at $72^{\circ} \mathrm{C}$ for $5 \mathrm{~min}$. The PCR products of 360-bp were purified using Accuprep Bioneer's PCR purification kit (Bioneer, Daejeon, Korea), and digested with MluI (New England Biolabs, Beverly, MA, USA) (Fig. 1A). The digested fragments were analyzed on $2 \%$ agarose gel. Upon digestion with $M l u \mathrm{I}$, the A allele was cleaved into two fragments (290- and 70-bp), whereas the G allele was identified by a single band (360-bp) (Fig. 1B).

Biochemical determinations. Blood samples from the PCOS patients and controls were analyzed using biochemical assays, including FSH, LH, TSH, PRL, DHEA-S and E2.

Statistical analysis. Genotype frequencies of the patients and control samples were compared using the $\chi^{2}$ test, and analyzed using HapAnalyzer (NGRI, Seoul, Korea; www.hap.ngri.re.kr). $\mathrm{P}<0.05$ was considered to be statistically significant. To verify whether the haplotypes in the -866G/A polymorphism of $U C P 2$ were associated with PCOS, the results were compared using HapAnalyzer.

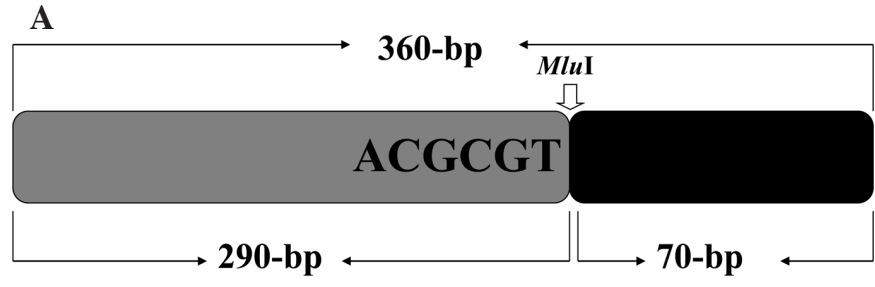

360-bp : Homozygosity for the G allele

290- and 70-bp : Homozygosity for the A allele

360-, 290- and 70-bp : Heterozygosity for the $G$ and $A$ allele

\section{B}

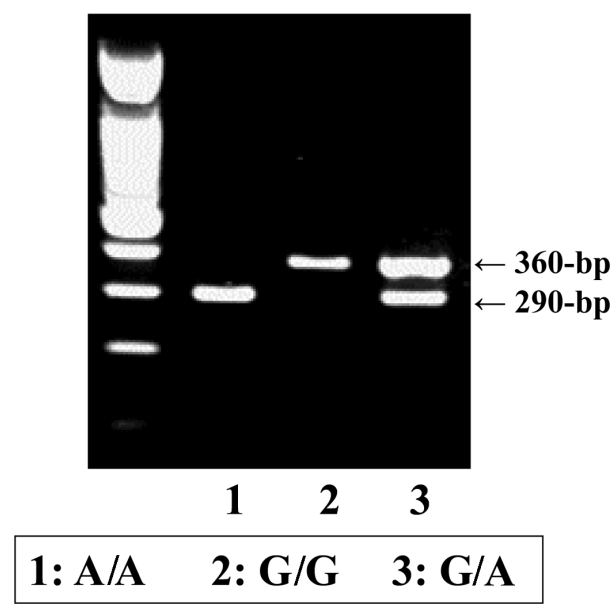

Figure 1. (A) Structure of the $U C P 2$ gene. The arrow indicates the restriction site of the $U C P 2$ gene by $M l u \mathrm{I}$. MluI restricts the site and produces two fragments, 290- and 70-bp in the sequence containing the A allele. The sequence containing the $\mathrm{G}$ allele yields only one fragment of 360-bp. (B) G/A polymorphism of the $U C P 2$ gene. The A allele is restricted by $M l u \mathrm{I}$. Agarose gel electrophoresis (2\%) with ethidium bromide staining followed $M l u \mathrm{I}$ digestion of the PCR product. The single band shows 360-bp of the G/G genotype. Homozygosity of A allele has two bands of 290- and 70-bp. However, the $70-\mathrm{bp}$ band is not detected on the $2 \%$ agarose gel. Three bands of 360-, 290- and 70-bp indicate the G/A type.

\section{Results}

The 2003 ASRM/ESHRE Rotterdam consensus was adhered to for the diagnostic criteria of PCOS in order to recruit patients into the study (24-25). According to this standard, PCOS may be diagnosed when patients exhibit two of three phenotypes, i.e., oligo- or amenorrhea, clinical or biochemical hyperandrogenism and ultrasonographic polycystic ovarian morphology $(1,3,4)$. The analysis of clinical and biochemical characteristics revealed a significant difference between the PCOS and control groups in the levels of LH, TSH, DHEA-S and testosterone. The LH level in PCOS patients was found to be 2-fold higher than that in the control group (Table I). The results obtained from the biochemical analysis on the PCOS patient group revealed that 55 patients $(19.86 \%)$ were susceptible to hyperandrogenism and oligo- or amenorrhea, 45 (16.24\%) had hyperandrogenism and polycystic ovaries (PCOS), 129 (46.57\%) had oligo- or amenorrhea and polycystic ovaries, and 48 (17.33\%) had hyperandrogenism, oligo- or amenorrhea and polycystic ovaries. These data are recorded in Table II. 
Table I. Biochemical and clinical characteristics of normal controls and PCOS patients.

\begin{tabular}{lrr}
\hline Characteristics & \multicolumn{1}{c}{$\begin{array}{c}\text { Controls } \\
(\mathrm{n}=152)\end{array}$} & \multicolumn{1}{c}{$\begin{array}{c}\text { PCOS patients } \\
(\mathrm{n}=277)\end{array}$} \\
\hline BMI $\left(\mathrm{kg} / \mathrm{m}^{2}\right)$ & $20.75 \pm 2.39(16.38-38.32)$ & $22.49 \pm 2.48(16.88-29.68)$ \\
Waist/hip ratio $(\mathrm{WHR})$ & $0.85 \pm 0.078(0.73-0.95)$ & $0.89 \pm 0.02(0.71-1.15)$ \\
FSH levels $(\mathrm{mIU} / \mathrm{ml})$ & $6.89 \pm 1.88(3.29-9.79)$ & $5.17 \pm 1.19(2.86-18.58)$ \\
LH levels $(\mathrm{mIU} / \mathrm{ml})$ & $3.28 \pm 1.66(2.51-11.55)$ & $7.00 \pm 5.88(1.00-21.00)$ \\
E2 levels $(\mathrm{pg} / \mathrm{ml})$ & $34.97 \pm 27.88(4.79-218.09)$ & $31.79 \pm 18.45(8.00-86.50)$ \\
Prolactin levels $(\mathrm{ng} / \mathrm{ml})$ & $14.42 \pm 6.48(5.10-42.60)$ & $12.64 \pm 9.98(6.30-68.30)$ \\
TSH levels $(\mu \mathrm{IU} / \mathrm{ml})$ & $1.88 \pm 0.98(0.05-4.08)$ & $2.42 \pm 1.28(0.56-12.56)$ \\
DHEA-S levels $(\mu \mathrm{g} / \mathrm{dl})$ & $142.46 \pm 35.26(56.63-236.20)$ & $187.04 \pm 54.54(38.00-350.20)$ \\
Testosterone $(\mathrm{ng} / \mathrm{ml})$ & $0.23 \pm 0.14(0.03-0.54)$ & $0.47 \pm 0.24(0.15-0.89)$
\end{tabular}

BMI, body mass index.

Table II. Comparison of disorders/symptoms between the control group and PCOS patients.

\begin{tabular}{lcc}
\hline Characteristics & $\begin{array}{c}\text { Controls } \\
(\mathrm{n}=152)(0 \%)\end{array}$ & $\begin{array}{c}\text { PCOS patients } \\
(\mathrm{n}=277)(\%)\end{array}$ \\
\hline $\begin{array}{l}\text { Hyperandrogenism and } \\
\text { oligo- or amenorrhea }\end{array}$ & $\mathrm{n}=0$ & $\mathrm{n}=55(19.86)$ \\
$\begin{array}{l}\text { Hyperandrogenism and } \\
\text { polycystic ovaries }\end{array}$ & $\mathrm{n}=0$ & $\mathrm{n}=45(16.24)$ \\
$\begin{array}{l}\text { Oligo- or amenorrhea } \\
\text { and polycystic ovaries }\end{array}$ & $\mathrm{n}=0$ & $\mathrm{n}=129(46.57)$ \\
$\begin{array}{l}\text { Hyperandrogenism, } \\
\text { oligo- or amenorrhea and } \\
\text { polycystic ovaries }\end{array}$ & $\mathrm{n}=0$ & $\mathrm{n}=48(17.33)$ \\
\hline
\end{tabular}

Table III. Genotypes and allele frequencies of the $-866 \mathrm{G} / \mathrm{A}$ polymorphism of the UCP2 gene in women with PCOS and the controls group.

\begin{tabular}{lrrr}
\hline $\begin{array}{l}\text { Polymorphism } \\
\text {-866G/A }\end{array}$ & $\begin{array}{c}\text { PCOS } \\
(\mathrm{n}=277)\end{array}$ & $\begin{array}{l}\text { Controls } \\
(\mathrm{n}=152)\end{array}$ & P-value \\
\hline Genotypes, no. $\%)$ & & & \\
A/A & $57(20.6)$ & $38(25.0)$ & \\
G/A & $157(56.7)$ & $68(44.7)$ & 0.7168 \\
G/G & $63(22.7)$ & $46(30.3)$ & \\
Alleles, no. (\%) & & & \\
A & $271(48.9)$ & $144(47.4)$ & \\
G & $283(51.1)$ & $160(52.6)$ & \\
\hline
\end{tabular}

In order to perform genotypic analysis of the $-866 \mathrm{G} / \mathrm{A}$ polymorphism in the promoter of the UCP2 gene, PCR-RFLP analysis was carried out on the 277 PCOS patients and
152 controls. As a result, the frequency of A/A, G/A and G/G genotypes was revealed to be in similar proportion in both the PCOS and control groups (Table III). The frequency of the A/A genotype in the PCOS and control groups was 20.6 vs. 25\%, respectively; the frequency of the G/A genotype in the PCOS and control groups was 56.7 vs. $44.7 \%$, respectively; and the frequency of the G/G genotype in the PCOS and control groups was 22.7 vs. $30.3 \%$, respectively. These results reveal that there is no significant difference between the PCOS and control groups, indicating that no association exists between the $-866 \mathrm{G} / \mathrm{A}$ polymorphism in the promoter of the UCP 2 gene and PCOS.

\section{Discussion}

UCP plays a key role in the regulation of human energy metabolism by dissipating proton gradients, uncoupling respiration from oxidative phosphorylation, and converting fuel to heat (26). In numerous studies, $-866 \mathrm{G} / \mathrm{A},-55 \mathrm{C} / \mathrm{T}$ and 45-bp insertion/deletion of the gene polymorphism were reported for UCP2 $(10,18)$. Among them, -866G/A SNP was identified in the promoter region (17). Notably, this variant is reportedly associated with fat metabolism, obesity and diabetes in the majority of the population studied, including a Korean population (18). The minor A allele variant was frequently reported to be associated with increased adipose mRNA expression in vivo and with a modest reduction in obesity $(17,27)$. The $-866 \mathrm{~A}$ allele carrier is generally susceptible to developing diabetes due to a reduced insulin response to intravenous and oral glucose $(19,28)$. In addition, when an intravenous glucose tolerance test was performed, the results showed $-866 \mathrm{~A}$ allele carriers have a lower insulin secretion, and a reduced risk of diabetic neuropathy (29). Carriers of the $-866 \mathrm{~A}$ allele of the UCP2 gene are reported to have a reduced risk of coronary artery disease (30), depleted energy levels in the peripheral nerve function (31), a higher waist-to-hip ratio, a high risk of metabolic syndrome (32) and higher plasma markers of oxidative stress (33). 
The $-866 \mathrm{G}$ allele was shown to be associated with a reduced mRNA expression in adipose tissue, decreased transcriptional activity, high BMI, fat mass changes (34), increased risk of obesity $(17,18,21)$, high insulin response to glucose and a reduced risk of T2D (10,17-19). Carriers of the $-866 \mathrm{G}$ allele of $U C P 2$ are reported to have low blood triglyceride levels, high insulin sensitivity $(10,19)$ and higher levels of low-density lipoprotein (LDL) cholesterol (35). Taken together, the results showed that the $-866 \mathrm{G}$ allele was found to increase the risk of T2D and obesity compared to the $-866 \mathrm{G} / \mathrm{A}$ and $-866 \mathrm{~A}$ alleles (35). Additionally, 45 insertion/deletion polymorphisms of the $U C P 2$ gene have been reported to be strongly associated with BMI in a Korean population (36). Taking all of the data into consideration, it is assumed that since the UCP 2 gene is associated with T2D and obesity, it is also associated with obesity in females with PCOS.

The aim of the present study was to analyze the association between the $-866 \mathrm{G} / \mathrm{A}$ polymorphism of the UCP2 gene and PCOS in Korean females. In conclusion, these results indicate that no significant association exists between the $-866 \mathrm{G} / \mathrm{A}$ polymorphism in the promoter of the $U C P 2$ gene and PCOS in Korean females. The $-866 \mathrm{G} / \mathrm{A}$ polymorphism of $U C P 2$ was reported to be associated with obesity, insulin resistance and hyperinsulinemia but not associated with PCOS in patients who share common characteristic symptoms. Thus, this genetic association study provides no evidence for the involvement of the $-866 \mathrm{G} / \mathrm{A}$ polymorphism in the promoter of the UCP2 gene in PCOS patients in the Korean population. Further investigation of associations between the $-866 \mathrm{G} / \mathrm{A}$ polymorphism of the UCP2 gene and PCOS patients of different ethnic groups is required.

\section{Acknowledgements}

The authors sincerely thank Suresh Ramakrishna for his helpful discussion on the manuscript. This study was supported by a grant from the Korea Health 21 R\&D Project, Ministry of Health and Welfare, Korea (01-PJ10-PG6-01 GN13-0002).

\section{References}

1. Sheehan MT: Polycystic ovarian syndrome: diagnosis and management. Clin Med Res 2: 13-27, 2004.

2. Chang WY, Knochenhauer ES, Bartolucci AA and Azziz R: Phenotypic spectrum of polycystic ovary syndrome: clinical and biochemical characterization of the three major clinical subgroups. Fertil Steril 83: 1717-1723, 2005.

3. Badawy A and Elnashar A: Treatment options for polycystic ovary syndrome. Int J Womens Health 3: 25-35, 2011.

4. Stankiewicz M and Norman R: Diagnosis and management of polycystic ovary syndrome: a practical guide. Drugs 66: 903-912, 2006

5. Gambineri A, Pelusi C, Vicennati V, Pagotto U and Pasquali R: Obesity and the polycystic ovary syndrome. Int J Obes Relat Metab Disord 26: 883-896, 2002.

6. Choi SW, Gu BH, Ramakrishna S, Park JM and Baek KH: Association between a single nucleotide polymorphism in MTHFR gene and polycystic ovary syndrome. Eur J Obstet Gynecol Reprod Biol 145: 85-88, 2009.

7. Lee EJ, Oh B, Lee JY, Kimm K, Lee SH and Baek KH: A novel single nucleotide polymorphism of INSR gene for polycystic ovary syndrome. Fertil Steril 89: 1213-1220, 2008.

8. Pasquali R and Casimirri F: The impact of obesity on hyperandrogenism and polycystic ovary syndrome in premenopausal women. Clin Endocrinol (Oxf) 39: 1-16, 1993.
9. Elbein SC, Chu W, Ren Q, Wang H, Hemphill C and Hasstedt SJ: Evaluation of apolipoprotein A-II as a positional candidate gene for familial type II diabetes, altered lipid concentrations, and insulin resistance. Diabetologia 45: 10261033, 2002.

10. Dalgaard LT and Pedersen O: Uncoupling proteins: functional characteristics and role in the pathogenesis of obesity and type II diabetes. Diabetologia 44: 946-965, 2001.

11. Nicholls DG, Snelling R and Rial E: Proton and calcium circuits across the mitochondrial inner membrane. Biochem Soc Trans 12: 388-390, 1984.

12. Fleury C, Neverova M, Collins S, et al: Uncoupling protein-2: a novel gene linked to obesity and hyperinsulinemia. Nat Genet 15: 269-272, 1997.

13. Wang H, Chu WS, Lu T, Hasstedt SJ, Kern PA and Elbein SC: Uncoupling protein-2 polymorphisms in type 2 diabetes, obesity, and insulin secretion. Am J Physiol Endocrinol Metab 286: E1-E7, 2004

14. Saleh MC, Wheeler MB and Chan CB: Uncoupling protein-2: evidence for its function as a metabolic regulator. Diabetologia 45: 174-187, 2002.

15. Zhang CY, Baffy G, Perret P, et al: Uncoupling protein-2 negatively regulates insulin secretion and is a major link between obesity, beta cell dysfunction, and type 2 diabetes. Cell 105: 745-755, 2001.

16. Heidari J, Akrami SM, Heshmat R, Amiri P, Fakhrzadeh H and Pajouhi M: Association study of the $-866 \mathrm{G} / \mathrm{A}$ UCP2 gene promoter polymorphism with type 2 diabetes and obesity in a Tehran population: a case control study. Arch Iran Med 13: 384-390, 2010.

17. Esterbauer H, Schneitler C, Oberkofler H, et al: A common polymorphism in the promoter of UCP2 is associated with decreased risk of obesity in middle-aged humans. Nat Genet 28: 178-183, 2001.

18. Jia JJ, Zhang X, Ge CR and Jois M: The polymorphisms of UCP2 and UCP3 genes associated with fat metabolism, obesity and diabetes. Obes Rev 10: 519-526, 2009.

19. Krempler F, Esterbauer H, Weitgasser R, et al: A functional polymorphism in the promoter of UCP2 enhances obesity risk but reduces type 2 diabetes risk in obese middle-aged humans. Diabetes 51: 3331-3335, 2002.

20. Yu X, Wieczorek S, Franke A, et al: Association of UCP2-866G/A polymorphism with chronic inflammatory diseases. Genes Immun 10: 601-605, 2009.

21. Vogler S, Goedde R, Miterski B, et al: Association of a common polymorphism in the promoter of UCP2 with susceptibility to multiple sclerosis. J Mol Med 83: 806-811, 2005.

22. Palmer BR, Devereaux CL, Dhamrait SS, et al: The common G-866A polymorphism of the UCP2 gene and survival in diabetic patients following myocardial infarction. Cardiovasc Diabetol 8: 31, 2009.

23. Caro JF: Clinical review 26: insulin resistance in obese and nonobese man. J Clin Endocrinol Metab 73: 691-695, 1991.

24. Rotterdam ESHRE/ASRM-Sponsored PCOS Consensus Workshop Group: Revised 2003 consensus on diagnostic criteria and long-term health risks related to polycystic ovary syndrome. Fertil Steril 81: 19-25, 2004.

25. Li L, Yun JH, Lee JH, Song S, Choi BC and Baek KH: Association study of $+45 \mathrm{G} 15 \mathrm{G}(\mathrm{T} / \mathrm{G})$ and $+276(\mathrm{G} / \mathrm{T})$ polymorphisms in the adiponectin gene in patients with polycystic ovary syndrome. Int J Mol Med 27: 283-287, 2011.

26. Chan CB and Kashemsant N: Regulation of insulin secretion by uncoupling protein. Biochem Soc Trans 34: 802-805, 2006.

27. Le Fur S, Le Stunff C, Dos Santos C and Bougneres P: The common $-866 \mathrm{G} / \mathrm{A}$ polymorphism in the promoter of uncoupling protein 2 is associated with increased carbohydrate and decreased lipid oxidation in juvenile obesity. Diabetes 53: 235-239, 2004.

28. Gable DR, Stephens JW, Cooper JA, Miller GJ and Humphries SE: Variation in the UCP2-UCP3 gene cluster predicts the development of type 2 diabetes in healthy middle-aged men. Diabetes 55: 1504-1511, 2006.

29. Rudofsky G Jr, Schroedter A, Schlotterer A, et al: Functional polymorphisms of UCP2 and UCP3 are associated with a reduced prevalence of diabetic neuropathy in patients with type 1 diabetes. Diabetes Care 29: 89-94, 2006.

30. Cheurfa N, Dubois-Laforgue D, Ferrarezi DA, et al: The common $-866 \mathrm{G}>\mathrm{A}$ variant in the promoter of UCP2 is associated with decreased risk of coronary artery disease in type 2 diabetic men. Diabetes 57: 1063-1068, 2008. 
31. Yamasaki H, Sasaki H, Ogawa K, et al: Uncoupling protein 2 promoter polymorphism -866G/A affects peripheral nerve dysfunction in Japanese type 2 diabetic patients. Diabetes Care 29: 888-894, 2006.

32. Shen H, Qi L, Tai ES, Chew SK, Tan CE and Ordovas JM Uncoupling protein 2 promoter polymorphism -866G/A, central adiposity, and metabolic syndrome in Asians. Obesity (Silver Spring) 14: 656-661, 2006

33. Stephens JW, Dhamrait SS, Mani AR, Acharya J, Moore K, Hurel SJ and Humphries SE: Interaction between the uncoupling protein $2-866 \mathrm{G}>\mathrm{A}$ gene variant and cigarette smoking to increase oxidative stress in subjects with diabetes. Nutr Metab Cardiovasc Dis 18: 7-14, 2008

34. Yoon Y, Park BL, Cha MH, Kim KS, Cheong HS, Choi YH and Shin HD: Effects of genetic polymorphisms of UCP2 and UCP3 on very low calorie diet-induced body fat reduction in Korean female subjects. Biochem Biophys Res Commun 359: 451-456, 2007.
35. Reis AF, Dubois-Laforgue D, Bellanne-Chantelot C, Timsit J and Velho G: A polymorphism in the promoter of UCP2 gene modulates lipid levels in patients with type 2 diabetes. Mol Genet Metab 82: 339-344, 2004.

36. Lee YH, Kim W, Yu BC, Park BL, Kim LH and Shin HD: Association of the ins/del polymorphisms of uncoupling protein 2 (UCP2) with BMI in a Korean population. Biochem Biophys Res Commun 371: 767-771, 2008. 